\title{
Justiça de Transição, Cultura Política e Legado Autoritário no Cone Sul
}

\author{
Maíra Pereira da Costa \\ Universidade Federal do Rio Grande do Sul \\ Rodrigo Stumpf González \\ Universidade Federal do Rio Grande do Sul
}

\section{Introdução}

Entre a metade dos anos 1970 e a o início da década de 1990 inúmeros países com regimes considerados autoritários liberalizaram-se e fizeram reformas em direção à democracia, no que foi caracterizado por Samuel Huntington como Terceira Onda (Huntington, 1994). Na América Latina, marcada por regimes militares inseridos no contexto político da Guerra Fria, esse processo tem início em meados dos anos 1970, com aberturas políticas como a ocorrida no Brasil que culminaram no fim da ditadura em diversos países, começando com o Peru em 1980 e envolvendo, entre outros, Argentina (1983), Brasil (1985) e Uruguai (1985) (Huntington, 1994; O’Donnell, Schmmitter e Whitehead, 1987).

Os estudos sobre a transição dos regimes autoritários para a democracia e sua posterior consolidação centraram-se, em um primeiro momento, na análise dos atores envolvidos e na construção de instituições representativas (O’Donnell, Schmitter e Whitehead, 1987, 1988; Linz, 1986).

Os regimes autoritários do Cone Sul foram caracterizados não só pelas graves violações de direitos humanos, cometidas pelos Estados, e pela adesão à Doutrina de Segurança Nacional (DSN), mas também pela implementação de instituições, valores e orientações que acabaram por deixar um legado autoritário que se perdurou na posterior democratização (Padrós, 2008; Cerveira, 2009; De Souza, 2011). O avanço do comunismo passou a ser considerado como a grande ameaça e justificativa para as ações autoritárias e o combate ao inimigo interno a prioridade (Napolitano, 2014).

A questão de como lidar com as consequências do passado autoritário, em relação à reparação de danos e à construção da memória, como um dos desafios para a construção e consolidação da democracia, tem sido o objeto do campo da Justiça de Transição (Teitel, 2003; Abrão e Genro, 2013; Machado, 2014).

Para além dos aspectos institucionais da democracia, outra abordagem buscou discutir seu fundamento na cultura política, ou como as atitudes, valores e crenças se relacionam com o apoio da população à manutenção do regime democrático (Moisés, 2008; Baquero, 2011a; Paiva, Souza e Lopes, 2004).

Dentro desta perspectiva, este estudo busca discutir a relação entre a utilização de instrumentos de Justiça de Transição como uma forma de transformar os legados autoritários e a construção de uma cultura política que favoreça a democracia. São analisadas comparativamente as iniciativas de justiça de transição adotadas por Argentina, Brasil, Chile e 
Uruguai e sua relação com a cultura política destes países no momento presente, bem como os possíveis impactos nos seus respectivos regimes para o futuro.

São apresentados os processos de transição dos países do Cone Sul e o uso de instrumentos de justiça de transição, seja no momento inicial da transição, seja tardiamente. Acrescido a isso, a perspectiva dos cidadãos em relação à democracia e sua percepção sobre o passado autoritário são discutidos com base nos dados do World Values Survey e na cobertura feita pelos principais jornais destes países. Discute-se, ao final, a relação entre as diferenças como cada país enfrentou a transição e tratou dos legados do autoritarismo e as características presentes da cultura política, tentando identificar elementos que permitam apontar se o uso da justiça de transição se efetiva como elemento de socialização política favorável à democracia.

\section{Democratização à luz da Cultura Política: legados autoritários, justiça de transição e memória}

Sem entrar no longo debate em torno do conceito de democracia (Held, 1987), há uma diferença marcada entre modelos minimalistas e aqueles que entendem a democracia em um sentido mais amplo, contemplando uma dimensão normativa, aspectos sociais e econômicos (Moisés, 1995, 2008).

Os modelos minimalistas concebem a democracia predominantemente a partir de sua dimensão procedimental, definindo-a enquanto um método de escolha dos governantes (Schumpeter, 1984; Moisés, 2008), com a existência de eleições livres e limpas, processo que depende da escolha dos atores envolvidos, seus pactos e regras (Santos e Baquero, 2007; Baquero, 2012).

Já as perspectivas maximalistas vão além da dimensão estritamente formal e procedimental da democracia, visto que defendem que apenas condições mínimas são insuficientes para estabelecer tal regime, o qual necessita também de condições econômicas, culturais e sociais. Isto posto, consideram que não é possível falar em sustentação da democracia sem um apoio normativo (Santos e Baquero, 2007), o que compreende, portanto, a dimensão da cultura política enquanto um fator essencial para a construção e manutenção dos regimes democráticos.

Desse modo, considera-se fundamental, para além das dimensões institucional e legal, um conjunto de valores e atitudes, bem como uma base normativa que sustenta a legitimidade do regime, para o melhor funcionamento da democracia (Baquero, 2011b). Partindo desta perspectiva, um dos principais desafios para a (re)construção democrática é o de fomentar atitudes, valores e comportamentos que valorizem as práticas e ideais democráticos (Baquero e González, 2011).

As transições para a democracia trazem, portanto, diversos outros desafios, já que não se trata de um processo linear, mas sim uma trajetória com avanços e retrocessos ao equacionar os interesses em disputa (Linz, 1986). Ademais, não é um processo com um único caminho, dependendo de inúmeros fatores internos e externos (Barahona e Sznajder, 2010).

Além de elementos institucionais, as novas democracias trazem consigo questões de cunho cultural e valorativo que impactam na sua consolidação (Aguilar, Balcells e Cebolla, 2011). Nesse sentido, pensar a consolidação democrática na América Latina também é pensar em como os valores, expectativas e comportamentos se constituíram e se (re) produziram. Isso 
é relevante especialmente em um contexto como o latinoamericano, marcado por constantes interrupções autoritárias que reduziram a possibilidade de construção e consolidação de uma base de apoio à democracia. Além disso, a América Latina transitou para a democracia sem construir organizações e reforçar valores democráticos (Baquero, 2011a), o que aumenta o desafio da construção democrática.

Com o advento das transições, as antigas estruturas, práticas e valores não são simplesmente erradicados. A transição marca a mudança institucional, mas resquícios ainda permanecem, visto que as mudanças são gradativas (Morlino, 2010; Pinto e Martinho, 2014). Morlino e Hite, falam, então, em legados autoritários, que

abrangem todos os padrões comportamentais, regras, relações, situações sociais e políticas, e também normas, procedimentos e instituições, introduzidos ou reforçados e amplamente fortalecidos pelo regime autoritário imediatamente anterior (Hite e Morlino, 2004, p. 24).

Os legados estão intimamente imbricados numa dinâmica de continuidade de um fenômeno que existiu anteriormente e estão presentes em diversas esferas sociais, tanto nas instituições formais quanto no que concerne a práticas e experiências que ligam a sociedade civil ao Estado. Ademais, podem se manifestar tanto na dimensão institucional, reforçando valores anteriores através de novas instituições, quanto criando e/ou reproduzindo hábitos e comportamentos (Morlino, 2004, 2010). Em suma: a transição pura e simples não basta para a construção de um regime democrático sólido, e os legados autoritários são um obstáculo para esse processo de construção.

Considerando essa dimensão de valores e legitimidade social, levanta-se a seguinte questão: como esses valores vão sendo construídos e consolidados? Esse conjunto de valores, atitudes e comportamentos permeiam as instituições, moldando-as, assim como tem uma íntima relação com as condutas na vida em sociedade, processo no qual a socialização política tem grande contribuição. Por isso a proposta deste trabalho de verificar como um conjunto de práticas - as medidas de Justiça de Transição - podem afetar a Cultura Política, entendendo que tais práticas poderiam ter uma contribuição positiva para a construção de uma Cultura Política de valorização da democracia frente ao autoritarismo ao influenciarem a socialização política, processo que tem a memória social enquanto um elemento constitutivo.

\section{Justiça de Transição no Cone Sul: iniciativas de Brasil, Argentina, Chile e Uruguai}

A discussão sobre a consolidação contribuiu para a emergência dos estudos sobre Justiça de Transição. Nesse sentido, apesar da necessidade de punir abusos remeter à antiguidade, somente depois dos tribunais de Nuremberg e Tóquio, após a Segunda Guerra Mundial, iniciativas voltadas ao modo de lidar com as mais diversas dimensões do passado de abusos se tornaram um aspecto relevante para a mudança de regime (Teitel, 2003; Elster, 2004; Barahona, 2009).

De acordo com Antonio Costa Pinto (2014), a Justiça de Transição é relativa a um conjunto de atitudes e decisões adotadas frente ao passado autoritário, constituindo um processo que envolve diversas medidas tomadas durante a democratização e que extrapolam a simples persecução penal da elite autoritária e seus colaboradores, contemplando também uma série de 
esforços extrajudiciais. Além disso, relaciona-a um componente intimamente ligado à democratização, sendo um processo de mudança de regime que ocorre entre a decomposição do autoritarismo e a reconstrução da democracia. Desse modo, é possível definir Justiça de Transição enquanto uma estrutura composta por um conjunto de mecanismos e práticas para enfrentar os abusos do passado e enquanto parte de um processo de transformação política. Para tanto, envolve estratégias judiciais e não-judiciais (Mezarobba, 2009; ONU, 2004; Pinto, 2014). Entre os mecanismos e iniciativas que podem ser adotados estão: a) Comissões da verdade; b) Responsabilização penal dos agentes envolvidos em crimes e violações de direitos humanos; c) Afastamento dos agentes públicos que colaboraram com os regimes; d) Reparação material e imaterial às vítimas; e) Reformas institucionais; f) Políticas de memória (Zyl, 2009; Olsen, Payne e Reiter, 2010; Greiff, 2012).

Considerando que o próprio conceito de Justiça de transição foi formulado após o fim de seus regimes autoritários, os países do Cone Sul adotaram estes mecanismos com diferentes ênfases, dependendo das circunstâncias em que se deram as transições e tratando de maneiras diversas seu passado autoritário. A seguir são analisados os casos.

\section{1 Brasil}

No caso brasileiro destaca-se que a Lei de Anistia, lei $n^{\circ} 6.683 / 79$, precedeu o retorno do poder aos civis, mas foi mantida após a democratização, tornando-se o marco inicial das reparações sobretudo econômicas - que aconteceriam posteriormente. Apesar de sua limitação ${ }^{1}$, uma vez que se tratou de uma anistia recíproca, contemplando também os agentes do Estado, limitando investigações e responsabilização penal por violações de direitos humanos, a aprovação da referida lei foi um dos marcos jurídicos fundantes do processo de redemocratização do país (Abrão e Torelly, 2012).

A primeira tentativa de elucidação do que ocorreu durante o período autoritário no Brasil se deu em 1979: o conjunto de dados que deu origem aos relatórios Nunca Mais, ancorados na pauta da "memória, verdade e justiça". Consistiram em um conjunto de levantamentos de prisões, mortes, desaparecimentos e torturas ocorridas durante o período autoritário a mando do Estado. No entanto, não foi uma iniciativa oficial do Estado, e sim de movimentos ligados à defesa de direitos humanos, familiares de mortos e desaparecidos e setores da Igreja Católica (Araujo, 2012). A proposição de um relato oficial, dentro do marco da Justiça de Transição, somente veio a ocorrer a partir de 2011.

A pauta referente às violações de direitos humanos e à memória do autoritarismo não esteve presente entre os pontos centrais negociados na passagem do poder dos militares para os civis em 1985 (González, 1994). Mais de uma década se passou até que no governo Fernando Henrique Cardoso começassem a ser elaboradas políticas de direitos humanos concretas (González, 2010). Assim, em 1995 foi editada a lei nº 9.140/95, que criou a Comissão Especial sobre Mortos e Desaparecidos Políticos (CEMDP), constituindo-se enquanto a ação que daria

\footnotetext{
${ }^{1} \mathrm{O}$ debate em torno de tal medida diz respeito à impossibilidade de persecução penal dos agentes do Estado responsáveis por violações de direitos humanos ocorridas durante a ditadura. A interpretação de anistia recíproca que vinha sendo aplicada sobre os crimes conexos foi mantida após uma decisão do Supremo Tribunal Federal, que declarou improcedente a Arguição de Descumprimento de Preceito Fundamental (ADPF) no 153 que versava sobre o tema (Machado, 2014; Gallo, 2016).
} 
a tônica do processo de Justiça de Transição brasileiro: a reparação econômica (Carvalho, 2015; Lentz, 2014).

Composta por familiares, representantes do Estado e das forças armadas, a Comissão teve como objetivos: "i) reconhecer as vítimas da ditadura que foram mortas ou estavam desaparecidas; ii) conceder indenização aos familiares; iii) localizar e identificar os restos mortais dos/das desaparecidos/as políticos/as" (Carvalho, 2016, p. 36). Assim, ao lado dos relatórios Nunca Mais, contribuiu timidamente para a construção de uma narrativa sobre o período autoritário até então negligenciada - ou negada - pelo Estado e pela sociedade.

Posteriormente, em 2001 foi criada a Comissão de Anistia, que concentra os requerimentos de anistia de perseguidos políticos entre 1946 e 1988. Tal comissão também foi responsável por uma iniciativa no âmbito das reparações simbólicas - as Caravanas da Anistia - que consistiram em sessões públicas itinerantes ocorridas em diversas cidades do Brasil, com atividades culturais voltadas à valorização dos direitos humanos no país (Abrão e Torelly, 2011; Carvalho, 2016; Gonçalves, 2014; Rubert, 2014).

A partir de 2007 houve uma aceleração no debate em torno da Justiça de Transição no Brasil, com demandas pela revisão da Lei da Anistia e pela criação de uma Comissão da Verdade (Carvalho, 2016). Nesse contexto, em 2008 foi ajuizada pela Ordem dos Advogados do Brasil a ADPF n ${ }^{\circ}$ 153, questionando a validade da Lei de Anistia; contudo, a interpretação de que é válida foi mantida.

Além disso, em 2009 foi lançado o III Plano Nacional de Direitos Humanos com um de seus eixos voltado à promoção do direito à memória e verdade, o que abriu portas e tornou mais sólida a possibilidade de instalação da Comissão Nacional da Verdade (CNV) anos depois. É importante destacar que seu lançamento foi alvo de ataques e esteve envolto a polêmicas por trazer, dentre outras coisas, o debate da possibilidade de investigação das violações de direitos humanos ocorridas entre 1964 e 1985, o que demonstra como tal tema ainda era muito sensível e controverso, mesmo 24 anos após o fim do regime autoritário no país.

Iniciativa tardia, a Comissão Nacional da Verdade foi criada no Brasil a partir da lei $\mathrm{n}^{\mathrm{o}}$ 12.528 de 18 de novembro de 2011, 47 anos após o golpe de 1964 e 36 anos depois do fim do regime militar, durante o governo da presidente Dilma Rousseff. Os trabalhos tiveram início em maio de 2012 e o relatório final foi apresentado em dezembro de 2014 . Trata-se da primeira iniciativa institucional voltada exclusivamente para revelar fatos políticos e históricos do nosso país após longo caminho de um processo no âmbito da justiça de transição (Lafer, 2012).

De modo geral, as iniciativas de Justiça de Transição brasileiras foram adotadas tardiamente. A reparação econômica, aspecto central do processo, foi iniciada dez anos após a redemocratização. As demais ações ocorreram ainda mais tarde, diferente do que ocorreu nos países vizinhos.

\subsection{Argentina}

À frente dos demais países do Cone Sul, a Argentina é considerada referência na América Latina, tanto pelos processos de persecução penal dos responsáveis por violações de direitos humanos e crimes de lesa-humanidade, quanto pela intensa participação de vítimas e familiares no que toca a pauta em torno da memória, verdade e justiça (Del Río, 2015). 
Vale ressaltar que a primeira medida de Justiça de Transição no país ocorreu logo após a eleição de Raúl Alfonsín para a presidência, devido à grande pressão da sociedade civil a respeito do desaparecimento de pessoas nos anos do regime. Assim, em 1984 iniciaram-se os trabalhos da Comisión Nacional de la Desaparición de Personas (CONADEP), comissão - que serviu de exemplo para as comissões em outros países - cujo objetivo era o de investigar e registrar os desaparecimentos, sequestros, tortura e apropriação de bebês e crianças durante o período autoritário (Acuña e Smulovitz, 1995; Carvalho e Duque, 2016). Após exaustivo trabalho, a Comissão encerrou suas atividades, fez diversas recomendações ao Estado e, em 1985, foi publicado o relatório Nunca Más, importante documento que contou com grande divulgação e consequente repercussão social, suscitando a demanda por justiça (Camacho, 2008), especialmente pela revelação de números expressivos de mortos e desaparecidos no país ${ }^{2}$, uma vez que o desaparecimento forçado foi o modos operandi da repressão no país (Padrós, 2014).

Ainda em 1985 ocorreu o emblemático Juicio a las Juntas, que contou com o relatório Nunca Más enquanto importante fonte de provas. Tratou-se do julgamento dos integrantes das três primeiras juntas militares da ditadura, que culminou na condenação de cinco dos nove acusados e centenas de oficiais julgados.

Contudo, o avanço das ações criminais provocou o descontentamento das Forças Armadas, criando uma ameaça à estabilidade democrática que estava sendo construída (Aguila, 2008). Nesse sentido, duas ações foram tomadas no intuito de limitar o processo de persecução penal (Parenti e Pellegrini, 2009; Carvalho e Duque, 2016). A primeira foi a promulgação da Ley de Punto Final, em 1986, lei que fixava um prazo para a apresentação de novas acusações e limitava o início aos trâmites legais, inocentando os oficiais que não fossem indiciados dentro do período estabelecido. Foi promulgada também a Ley de Obediencia Debida, isentando de responsabilidade penal os militares abaixo da patente de tenente-coronel que declararam ter agido em cumprimento de ordens superiores (Novaro e Palermo, 2007).

Além disso, em 1989 foram aprovados pelo presidente Carlos Menem os decretos de indulto que beneficiaram os militares processados e/ou condenados, em outra medida que foi de encontro ao processo de punição dos militares envolvidos em violações de direitos humanos.

No que diz respeito à reparação econômica, foi aprovada a lei 24.411/1994, possibilitando a concessão de indenização às vítimas e familiares de pessoas assassinadas e/ou desaparecidas.

As leis que impediam os julgamentos foram anuladas em 2003 no Congresso Nacional e em 2005 na Suprema Corte, possibilitando a continuidade dos processos, retomados no ano seguinte (Duque e Carvalho, 2016; Paixão et al, 2015; Guembe, 2005). Todos os membros das juntas militares e diversos oficiais envolvidos em atos de tortura e desaparecimentos foram condenados em sessões públicas, recebendo penas longas de privação de liberdade.

$\mathrm{Na}$ Argentina houve, ainda, uma iniciativa no âmbito de reforma institucional, com o afastamento de oficiais responsáveis por violações de direitos humanos no período autoritário.

\footnotetext{
${ }^{2} \mathrm{O}$ relatório da referida comissão contabilizou cerca de nove mil mortos e desaparecidos, mas cogita-se que o número real seja maior, como aponta Mendes (2013).
} 


\subsection{Chile}

Em 1990, logo no primeiro ano de reestabelecimento da democracia, foi criada a primeira comissão da verdade chilena voltada à investigação dos fatos e violações ocorridos no período autoritário, a Comisión Nacional de Verdad y Reconciliación (“Comissão Retting”), a qual não tinha competência para punir os agentes envolvidos nos crimes apurados.

Em 1992 foi promulgada a Lei de Reparação e criada a Corporação Nacional para a Reparação e Reconciliação, iniciativas voltadas à reparação material das famílias de mortos e desaparecidos políticos (Dahás, 2012). Tempos depois, no início dos anos 2000, foi criada uma segunda comissão da verdade, exclusivamente dedicada à identificação de sobreviventes de prisão política e tortura, a Comissão Nacional sobre Prisão Política e Tortura (ou "Comissão Valech"), a partir da qual se elaborou o "Informe sobre a Prisão e a Tortura no Chile", ampliando os direitos de reparação econômica e simbólica aos novos nomes incluídos no relatório (Dalbora, 2009; Barbosa, Carvalho e Freitas, 2016; Paixão et al, 2015; Rojas, 2016).

O Chile se destaca pela criação de uma forte comunidade em defesa dos direitos humanos, com grande protagonismo da Igreja Católica, porém, apenas em 1998 as denúncias contra Pinochet repercutiram no cenário internacional. O ditador, no entanto, morreu em 2006 sem nenhuma condenação nos processos em que foi réu.

Deve-se ressaltar que mesmo com a vigência da Lei de Autoanistia promulgada em 1978, a partir de 2004 uma prática recorrente da Corte Suprema de Justiça e de tribunais inferiores foi o afastamento da anistia e da prescrição de casos reconhecidos enquanto crimes de lesahumanidade (Dalbora, 2009; Barbosa, Carvalho e Freitas, 2016), flexibilização presente nos demais países aqui analisados, exceto no Brasil.

Por fim, uma das mais importantes iniciativas chilenas de Justiça de Transição foi a inauguração do Museu da Memória e dos Direitos Humanos, em 2010.

\subsection{Uruguai}

Os limites dados pelo Pacto del Clube Naval, impossibilitaram a responsabilização penal dos agentes responsáveis por violações de direitos humanos, como parte de uma transição negociada (Galain Palermo, 2011, 2014; Corbo, 2007).

Posteriormente, foi aprovada em 1985 a primeira Lei de Anistia, que possibilitou a liberação de inúmeros civis presos, acusados de crimes políticos (Sosa, Mazzucchi, 2012). Esta lei não incluía os militares que cometeram crimes durante o período autoritário.

Em face das diversas denúncias contra os militares, editou-se a Ley de Caducidad de la Pretensión Punitiva del Estado, uma lei semelhante à Ley do Punto Final argentina, que beneficiou os militares envolvidos em crimes ao submeter a investigação dos fatos denunciados à decisão do Poder Executivo, o qual poderia ou não permitir as investigações caso a caso. Tal lei foi amplamente questionada por movimentos de direitos humanos e, em 1988, a Suprema Corte de Justicia do Uruguai declarou sua constitucionalidade, o que foi revisto anos mais tarde, no "caso Sabalsagaray", sem efeito erga omnes (Galain Palermo, 2014).

Em 1985 foram criadas a Comisión Investigadora sobre Situación de Personas Desaparecidas y Hechos que la Motivaram, para investigar os casos de crianças sequestradas, desaparecimento forçado e tortura nos centros clandestinos de detenção, e a Comisión 
Investigadora sobre el Secuestro y Asessinato Perpetrados contra los ex legisladores Héctor Gutiérres Ruiz y Zelmar Michelini, com objetivos mais específicos, como o próprio nome já diz (Galain Palermo, 2009; Nogueira e Carvalho, 2016).

Outra iniciativa foi a publicação do relatório Uruguay Nunca Más, de grande contribuição no âmbito da memória e da verdade. Contudo, tal qual no Brasil, não se tratou de uma medida oficial do Estado, mas sim a partir de uma organização ligada à Sociedade Civil (Servicio de Paz y Justicia). O relatório abrangeu as violações de direitos humanos ocorridas entre 1972 e 1985 (Galain Palermo, 2011).

Além disso, uma ação merece destaque enquanto marco da mobilização social no país em torno da pauta por memória, verdade e justiça: a Marcha del Silencio. Organizada pela primeira vez em 20 de maio de 1996, com protagonismo do movimento Madres y Familiares de Uruguayos Detenidos e Desaparecidos e ao lado de outras organizações, a marcha vem ocorrendo todos os anos desde então (Galain Palermo, 2014; Corbo, 2007).

Durante o mandato de Jorge Battle foi criada, ainda, a Comisión para la Paz, que teve como incumbência investigar os casos de desaparecimento durante o regime, com a coleta e classificação dos casos, sem, contudo, a possibilidade de investigar os responsáveis (Galain Palermo, 2009; Nogueira e Carvalho, 2016).

Em 2005 o então presidente Tabaré Vázquez admitiu a possibilidade de reinterpretação da Ley de Caducidad em casos específicos, especialmente quando se tratava de desaparecidos ou crianças, o que abriu espaço para a investigação. Tal flexibilização abriu caminhos para a declaração de inconstitucionalidade da lei anos depois (Galain Palermo, 2011, 2014).

Em 2006 uma iniciativa voltada à reparação material foi tomada, a partir da lei ${ }^{0} 18.033$, que concedeu indenização para pessoas que foram presas e/ou processadas no período compreendido entre 9 de fevereiro de 1973 e 28 de fevereiro de 1985. Já no que diz respeito à reparação simbólica, houve a abertura dos arquivos dos serviços de inteligência e repressão do Estado (Galain Palermo, 2009).

Em 2010 houve uma importante ação: a condenação do ex-presidente Juan María Bordaberry por homicídios durante o período autoritário, na condição de coautor. $\mathrm{O}$ expresidente foi responsabilizado criminalmente por ter facilitado as condições para a ocorrência dos crimes, bem como contribuir para a impunidade dos responsáveis (Galain Palermo, 2014).

Por fim, foi criado o Grupo de Trabajo por Verdad y Justicia, com ações voltadas às investigações de crimes de lesa-humanidade cometidos por agentes do Estado entre 1968 e 1985. O grupo, no entanto, segue com dificuldades de atuação.

Como pode ser visto no quadro 1, cada um dos países desenvolveu uma trajetória diferente na aplicação dos instrumentos de justiça de transição. 
Quadro 1 - Quadro sintético dos instrumentos de justiça de transição:

\begin{tabular}{|c|c|c|c|c|}
\hline Instrumentos & ARGENTINA & BRASIL & CHILE & URUGUAI \\
\hline Comissões da Verdade & Sim & Sim & Sim & Sim \\
\hline Julgamentos de agentes e oficiais & Sim & Não & Sim & Sim \\
\hline Leis de Impunidade elou Anistia & Sim (revogada) & Sim & Sim & Sim \\
\hline Reparações econômicas e simbólicas & Sim & Sim & Sim & Sim \\
\hline $\begin{array}{l}\text { Afastamentos de agentes e oficiais } \\
\text { militares }\end{array}$ & Sim & Não & Não & Não \\
\hline
\end{tabular}

Fonte: elaboração própria.

Para discutir a relação entre a aplicação destes instrumentos e os impactos dos legados autoritários na Cultura Política, a seguir são analisadas algumas características dos países nas dimensões de apoio à democracia e ao autoritarismo.

\section{Cultura Política e avaliação do passado autoritário}

A transição para a democracia marca a mudança institucional de regime; no entanto, permanecem os legados do regime anterior, os quais se manifestam em diversas dimensões (Morlino, 2010; Pinto, 2014). Desse modo, há a manutenção de comportamentos e atitudes autoritárias que podem apresentar limites às transformações pretendidas com o novo regime político (Moisés, 1995).

Como as práticas e instituições de um regime têm o potencial de inserir valores e comportamentos e fortalecer valores anteriores, os legados também podem ser identificados na dimensão da cultura política, influenciando, dentre outras coisas, a adesão - ou não - da população ao regime democrático, na preferência do regime democrático em detrimento de regimes autoritários, na confiança institucional e interpessoal e, claro, na participação política (Moisés, 2008; Gunther e Montero, 2005; Morlino, 2010; Baquero, 2011). Assim, podem estar relacionados à perspectiva sobre democracia e sobre o passado autoritário após a transição.

Apesar da indisponibilidade de dados sobre o comportamento, atitudes e valores anteriores aos regimes autoritários, é possível recorrer a dados pós redemocratização, buscando observar, ao longo do tempo, os valores em torno da democracia nos países do Cone Sul. Para tanto, lançamos mão de dados das ondas 3 (1995-1999), 5 (2005-2009) e 6 (2010-2014) do World Values Survey, com o intuito de observar o desenvolvimento dos valores a respeito da democracia e autoritarismo nos países do Cone Sul ao longo dos anos com uso da estatística descritiva, apresentados em suas frequências (Laville e Dione, 1999). Foram, então, selecionadas cinco variáveis relacionadas à avaliação da democracia e do autoritarismo por parte da população, que são elucidativas para o fim aqui proposto (WVS, 2019), ou seja, buscando identificar maior ou menor inclinação a preferir e apoiar um regime democrático, bem como repudiar ou não valores autoritários e o autoritarismo como forma de governo.

\subsection{Perspectiva sobre democracia e autoritarismo ao longo dos anos}

A realização de surveys que incluam todo o continente é um fenômeno recente na América Latina, datando da década de 1990, com a expansão do World Values Survey, posteriormente o Latinobarômetro, e mais recentemente o Barômetro das Américas (LAPOP). Em geral estas 
pesquisas voltam-se para a avaliação de valores presentes, não incluindo questões sobre avaliação do passado autoritário.

Neste trabalho optou-se utilizar os dados do World Values Surveys, por possuir uma bateria compreensiva de questões não somente sobre a democracia, mas incluindo a avaliação de alternativas autoritárias, em séries históricas que permitem a comparação entre os países.

\subsubsection{Valores em relação à democracia}

Na Tabela 1 são apresentadas as respostas de avaliação positiva de viver em uma democracia. Embora todos os países apresentem percentuais altos, nota-se uma diferença nas trajetórias de Brasil, em que este valor caiu no período recente, e Chile, que embora contasse com o menor percentual na primeira onda realizada nos anos 90 , passou a ter o maior percentual de apoio entre os quatro países.

Tabela 1 - Ter um sistema político democrático é: Respostas ótimo ou bom

\begin{tabular}{cccc}
\hline País Onda & $1995-1999$ & $2005-2009$ & $2010-2014$ \\
\hline Argentina & 89,9 & 87,2 & 85,2 \\
Brasil & 81,3 & 87,1 & 79,6 \\
Chile & 79,2 & 82,8 & 89,9 \\
Uruguai & 92,1 & 84,9 & 88,4 \\
\hline
\end{tabular}

Fonte: Elaboração própria a partir dos dados do World Values Survey.

Uma outra formulação de apoio a democracia é a resposta frente à afirmação de que a democracia é a melhor forma de governo, ainda que ela tenha problemas. Esta questão esteve presente apenas na onda 3 (1995-1999). Aqui são apresentados os resultados "concordo muito" e "concordo". Os resultados são semelhantes às respostas da questão apresentada na Tabela 1, com um percentual significativamente menor em Brasil e Chile com relação a Argentina e Uruguai.

Tabela 2 - A democracia é a melhor forma de governo ainda que tenha alguns problemas. Respostas concordo muito e concordo

\begin{tabular}{lc}
\hline Pais Onda & $1995-1999$ \\
\hline Argentina & 87,5 \\
Brasil & 79,1 \\
Chile & 77,2 \\
Uruguai & 90,9 \\
\hline
\end{tabular}

Fonte: Elaboração própria a partir dos dados do World Values Survey.

No entanto, os altos percentuais de defesa da democracia podem ser relativizados. A partir dos anos 1960 a democracia passa a ser defendida enquanto um valor, criando-se um consenso universal no mundo ocidental de se tratar do melhor regime para organizar a sociedade (Pinto, 1999, 2004). Nesse sentido, Céli Pinto afirma que "[...] a democracia se constitui frente à sua atual falta de inimigos" (Pinto, 2004, p. 19). Considerando isso, índices de apoio à democracia por si só são insuficientes para apontar essa defesa convicta, uma vez que raramente os indivíduos se colocarão completamente contra tal sistema de governo, ainda que de fato não 
pensem assim. Portanto, voltar-nos a variáveis sobre valores em relação ao autoritarismo se faz necessário.

\subsubsection{Valores em relação ao autoritarismo}

Uma das variáveis deste eixo diz respeito à avaliação da existência de um líder forte que não precise se preocupar com o parlamento ou eleições para governar, útil para identificar uma perspectiva autoritária e centralizadora do poder em detrimento de formas plurais de governar, com a existência de um processo eleitoral e um corpo de representantes.

A Tabela 3 mostra os que consideram "ótimo" ou "bom” ter um líder forte que não precise se preocupar com parlamento e eleições. O Brasil destoa dos demais com um percentual superior a $50 \%$ em todas as ondas. Os demais países têm percentuais próximos de $30 \%$, com o destaque nos casos de Uruguai e Argentina, em que este percentual tem um aumento importante, ficando relativamente inalterado apenas no Chile. Nos quatro países parece se manter uma parcela da população que parece considerar compatível aprovar a democracia, mas considerar eleições e debates parlamentares como desnecessários.

Tabela 3 - Ter um líder forte que não precise se preocupar com deputados e senadores e com eleições. Respostas ótimo e bom

\begin{tabular}{c|c|c|c}
\hline País Onda & $1995-1999$ & $2005-2009$ & $2010-2014$ \\
\hline Argentina & 27,6 & 32,1 & 44,6 \\
\hline Brasil & 57,9 & 62,1 & 64,8 \\
\hline Chile & 32,5 & 28,5 & 33,2 \\
\hline Uruguai & 23,8 & 31,2 & 30,9 \\
\hline
\end{tabular}

Fonte: Elaboração própria a partir dos dados do World Values Survey.

Questionados sobre a avaliação de ter um governo militar, vemos na Tabela 4 que os brasileiros novamente destoam dos demais países. Com índices acima de 30\% nas três ondas, é o país que melhor avalia o regime militar enquanto forma de governo, seguido do Chile. Embora em ambos os países estes valores tenham caído, ainda ficam acima de 30\% no Brasil. $\mathrm{Na}$ Argentina e no Uruguai ficaram próximo dos $10 \%$.

Tabela 4 - Ter um governo militar é ótimo ou bom

\begin{tabular}{|c|c|c|c|}
\hline País Onda & 1995-1999 & $2005-2009$ & 2010-2014 \\
\hline Argentina & 11,9 & 10,7 & 9,9 \\
\hline Brasil & 43,4 & 33,8 & 32,1 \\
\hline Chile & 27,6 & 16,7 & 16,5 \\
\hline Uruguai & 7,5 & 9,8 & 8,2 \\
\hline
\end{tabular}

A última questão selecionada para a análise diz respeito ao que os respondentes consideram características essenciais da democracia, e a afirmação apresentada aos entrevistados é se os militares podem assumir o poder quando o governo é incompetente. A Tabela 5 traz os dados das respostas, as quais foram distribuídas em uma escala de 1 a 10, em que 1 significa que o respondente considera a afirmação uma característica essencial da 
democracia e 10 não se trata de uma característica essencial da democracia. Com exceção do Brasil, nos demais países mais de $50 \%$ dos respondentes se posiciona nas respostas 1 e 2 , fortemente identificando que não é compatível com a democracia a intervenção militar. $\mathrm{O}$ percentual de brasileiros que considera que esta é uma característica essencial da democracia não apenas é bastante maior que nos demais casos, passando de $20 \%$ nas posições 9 e 10 , como aumentou nos últimos anos.

Tabela 5 - É uma característica da democracia que os militares possam assumir o poder se um governo é incompetente

\begin{tabular}{|c|c|c|c|c|c|c|c|c|}
\hline País & \multicolumn{2}{|c|}{ Argentina } & \multicolumn{2}{|c|}{ Brasil } & \multicolumn{2}{|c|}{ Chile } & \multicolumn{2}{|c|}{ Uruguai } \\
\hline Onda & 2005-2009 & 2010-2014 & $2005-2009$ & $2010-2014$ & $2005-2009$ & $2010-2014$ & 2005-2009 & 2010-2014 \\
\hline $\begin{array}{l}\text { Não é uma } \\
\text { característica } \\
\text { da democracia }\end{array}$ & 53,6 & 43,3 & 24,5 & 27,9 & 43,8 & 45,3 & 49,7 & 45,2 \\
\hline 2 & 4 & 11,2 & 7 & 5,4 & 8,4 & 9,1 & 8,1 & 11,1 \\
\hline 3 & 3,9 & 9,3 & 7,4 & 4,1 & 6 & 6,3 & 5 & 6,3 \\
\hline 4 & 2,2 & 6,2 & 7,1 & 3,8 & 3,8 & 6 & 4,5 & 3,2 \\
\hline 5 & 4,1 & 8,7 & 10,2 & 10,2 & 7,8 & 7,4 & 10,2 & 7,4 \\
\hline 6 & 2,9 & 4,4 & 4,2 & 5,9 & 4,5 & 4,8 & 3,9 & 3,2 \\
\hline 7 & 3 & 3,9 & 4,7 & 4,7 & 2,8 & 4,4 & 3,7 & 2,7 \\
\hline 8 & 3 & 3,7 & 7,7 & 5,8 & 3,1 & 3,4 & 2 & 5,4 \\
\hline 9 & 2,4 & 2,1 & 6 & 3,4 & 1,5 & 1,9 & 1,7 & 3 \\
\hline $\begin{array}{l}\text { É uma } \\
\text { característica } \\
\text { da democracia }\end{array}$ & 12,2 & 4 & 14,2 & 18,6 & 8,5 & 4,2 & 6,6 & 4,7 \\
\hline
\end{tabular}

A partir desses dados, o que se percebe é que, em geral, Argentina e Uruguai apresentaram índices de maior valorização da democracia e afastamento de aspectos autoritários, seguidos do Chile. Merece destaque, porém, o caso brasileiro. O Brasil, destoa dos demais países analisados, indicando maior tendência à relativização da democracia e apresentação de valores autoritários.

Não é possível determinar uma relação causal direta entre as transições democráticas de cada país e sua cultura política. Contudo, pode-se dizer que há a possibilidade de os legados autoritários de cada país impactarem esses valores, o que fica mais nítido com os índices do Brasil (Souza e Gallo, 2015).

\subsection{Interpretação e narrativa sobre o passado autoritário}

Interessa também de que maneira o passado autoritário tem sido tratado e avaliado. Isso porque as políticas de memória relacionam-se, de uma maneira mais ampla, à forma como a sociedade interpreta seu passado, visando (re)construir o futuro (Barahona e Sznajder, 2010), ou seja, de que maneira a narrativa sobre o passado é construída.

Pode-se apreender alguns indícios de como o autoritarismo ganha a dimensão pública, com maior ou menor ênfase em certos aspectos em cada país, se analisado o modo como assuntos relacionados à transição democrática e o regime autoritário foram tratados pela imprensa. 
Neste sentido Costa (2018) analisou quais os principais termos foram utilizados em alguns dos principais veículos impressos nos países estudados, em reportagens relacionadas com a questão da transição em um período recente ${ }^{3}$.

Os termos acompanham, em alguma medida, como se lidou com os legados do autoritarismo a partir das diferentes formas de enfrentá-los. Nas matérias do jornal argentino as palavras mais recorrentes foram direitos, golpe, humanos, justiça, memória, verdade, Estado, nunca, violência. Já no Brasil os destaques foram para ditadura, militar, golpe, anistia, Brasil, democracia, esquerda, nacional, revolução. Nas matérias do chileno El Mercurio foram muito citados Chile, país, direitos, humanos, governo, democracia, atos, verdade. E as palavras de maior destaque nas matérias uruguaias foram ditadura, direitos, Estado, justiça, país, verdade, desaparecidos, impunidade e vida (Costa, 2018).

A prevalência de vocábulos demonstra uma diferença de tratamento, com o caso brasileiro se destacando novamente. Enquanto termos como "direitos" e "verdade" estão presentes nos demais países, não são importantes no Brasil, onde surge a referência a "revolução", uma expressão cunhada pelos militares como legitimação do golpe de estado e anistia, como um tema presente mesmo depois de décadas da transição.

A diferença de tratamento pelos meios de comunicação é um indicativo de diferenças na aplicação dos instrumentos de justiça de transição na construção de narrativas e da memória do período autoritário. No caso brasileiro a questão dos direitos humanos não teve qualquer centralidade na transição e inclusive o termo adquiriu um tom pejorativo para parte da população (Caldeira, 1991).

A escolha dos termos como se aborda publicamente o passado foi construída pelo tratamento dado na transição, constituindo aquilo que se transformou em tabu (Douglas, 1976), tanto no sentido de sagrado (os direitos humanos, a verdade, a memória das vítimas), quanto de impuro (o golpe, os torturadores). Estas linhas parecem ter sido claramente delineadas na Argentina e no Uruguai, estão presentes de forma tênue no Chile, enquanto no Brasil aparentemente parte do tabu é tentar discutir o passado e construir a sua memória.

Os dados verificados no Brasil indicam valores autoritários e índices de avaliação positiva de um governo militar mais altos do que os demais países, além de menores índices de discordância em relação à associação da possibilidade de os militares poderem assumir quando um governo é incompetente ser uma característica constitutiva da democracia.

Um exemplo recente ocorreu em março de 2019, quando o presidente brasileiro Jair Bolsonaro, um ex-capitão do exército, de um partido conservador, determinou ${ }^{4}$ ao Ministério da Defesa que fossem feitas comemorações pelos 55 anos do golpe de estado de 31 de março de 1964. Já sobre a discussão em torno do termo "golpe" o porta-voz do governo deixou claro que o presidente não considera o ocorrido em março de 1964 um golpe, tampouco o regime ali instaurado uma ditadura, mas sim um "regime com autoridade".

\footnotetext{
${ }^{3}$ Os jornais analisados foram El Clarín (Argentina), Folha de São Paulo (Brasil), El Mercurio (Chile) e El País (Uruguai). Tais veículos de comunicação foram escolhidos por terem circulação em todo o país e estarem entre os de maior tiragem nacional, segundo dados de institutos de certificação Para mais detalhes ver: http://www.ivc.org.ar/boletin_xpress.html, https://www.ivcbrasil.org.br/\#/home e http://www.validachile.cl/valida/site/edic/base/port/inicio.html.

${ }^{4}$ Ver: https://g1.globo.com/politica/noticia/2019/03/25/bolsonaro-determinou-que-defesa-faca-ascomemoracoes-devidas-do-golpe-de-64-diz-porta-voz.ghtml.
} 
Essa diretriz e posicionamento vindo diretamente do Presidente da República tem grande importância simbólica e evidencia que a percepção positiva e, por vezes, nostálgica do passado autoritário é um legado sobre o qual não se conseguiu incidir no Brasil. Nas palavras de Marcos Napolitano, a "combinação de reparação, alguma verdade, e nenhuma justiça, portanto, tem sido o arremedo de uma política de memória do Estado brasileiro em relação ao regime" (Napolitano, 2014, p. 326).

\section{Considerações finais}

Este trabalho partiu da comparação entre os processos de transição para a democracia na Argentina, Brasil, Chile e Uruguai, buscando analisar como foram utilizados diferentes mecanismos de justiça de transição (ainda que tal nomenclatura nem existisse no momento de que algumas medidas foram tomadas) enquanto uma resposta aos legados do período autoritário, discutindo sua possiblidade de impactar a cultura política dominante. A presteza e a profundidade com que foram utilizados variou, com ênfase em reparações econômicas às vítimas e relatórios com efeito simbólico. Apenas na Argentina houve uma tentativa de ampla responsabilização penal dos violadores de direitos humanos.

A aplicação de iniciativas de Justiça de Transição nestes países denota a diferença na importância da pauta da violação de direitos humanos na agenda política no período póstransição, afetando também a capacidade de influenciar as narrativas históricas e a construção simbólica.

Também foram apresentadas as diferenças no que diz respeitos aos dados sobre atitudes e valores em relação à democracia e autoritarismo, com Argentina e Uruguai apresentando índices que demonstram maior apoio e apreço pelo regime democrático, bem como valores democráticos, seguidos de Chile, com índices um pouco diferentes (especialmente na questão a respeito da democracia ser considerada a melhor forma de governo), mas sem valores muito discrepantes. Já o Brasil, como foi dito, apresenta índices que diferem muito dos demais países, assim como é o único país em que se observou a possibilidade de uma avaliação pública positiva do regime militar o qual, por vezes, é enaltecido e reivindicado.

Alternativamente poderia se atribuir as diferenças de cultura política a trajetórias históricas diferentes, para além dos regimes autoritários mais recentes. Autores como Moisés (1995) ou Baquero (2012) chamam a atenção para a recorrência de traços autoritários entre os brasileiros.

Porém, ainda que Chile e Uruguai tenham vivido longos períodos de democracia política ao longo do século XX, a Argentina, que viveu como o Brasil situações recorrentes de autoritarismo e golpes de estado periódicos, aparentemente desenvolveu no período recente valores mais próximos da democracia que o Chile, com uma rejeição clara de um papel político dos militares.

Dos quatro países analisados três deles contaram, logo após a redemocratização, com iniciativas de justiça de transição para a elucidação dos fatos ocorridos durante o regime autoritário, exceto o Brasil. Enquanto logo na retomada da democracia foram adotadas medidas para lidar com as consequências do autoritarismo de uma perspectiva mais ampla e coletiva na Argentina, Chile e Uruguai, no Brasil a iniciativa central tratou da questão de modo individualizado, como algo relacionado majoritariamente às vítimas diretas do período, e não 
como uma questão envolvendo toda a sociedade. Além disso, na Argentina e Uruguai os membros dos governos militares foram totalmente deslegitimados, enquanto no Brasil e no Chile parte do Ancien Régime manteve seu poder e interferiu diretamente no processo político. Pinochet permaneceu como senador vitalício até ser declarado inválido. Mais de trinta anos depois do fim do regime os militares brasileiros recusam-se a fornecer informações sobre os mortos e desaparecidos na guerrilha do Araguaia.

Isso não significa que nos três primeiros países haja uma narrativa homogênea sobre o passado autoritário, que esse passado seja uma questão resolvida e superada, que em algum deles houve um processo de justiça de transição ideal ou, ainda, que os valores e atitudes em torno da democracia tenham sido construídos exclusivamente a partir do modo como se lidou com o passado autoritário. Contudo, indica a possibilidade de ser um elemento que contribui para uma avaliação negativa do que significou o autoritarismo e suas consequências social e politicamente danosas.

O presente trabalho buscou analisar a relação entre os mecanismos de justiça de transição e os legados autoritários, de como atuam no processo de redemocratização para além da dimensão institucional, influenciando também na construção de crenças e atitudes de valorização do regime democrático e sua preferência em detrimento de formas autoritárias.

Não é possível fazer uma relação de causalidade entre estes dados e a forma como a memória do autoritarismo foi tratada, mas pode-se propor que existe uma relação de pathdependence. Por isso pode ser considerada plausível a hipótese de que a forma como estes países desenvolveram seus mecanismos de justiça de transição afeta a construção de sua cultura política atual. Conforme a análise de processos proposta por George e Alexander (2005), embora não seja possível determinar o laço direto de causalidade, a evidência fortalece o argumento apresentado.

Nesse sentido, destaca-se a dimensão da memória, parte constitutiva de um processo de socialização política que contribui para a assimilação de opiniões, posicionamentos e ideais políticos; em suma, para o compartilhamento de sentido sobre a vida social e significantes simbólicos em uma sociedade (Barahona e Sznajder, 2010; Santos, 2002). Assim, está diretamente relacionada aos valores de uma sociedade, e tanto pode se configurar a partir da cultura política de um país, quanto pode contribuir para a construção de novas narrativas sobre um passado, o que, ainda que mais difícil - visto que "a durabilidade e penetração social de determinada versão do passado é maior quando esta é veiculada na esfera pública por instituições dominantes" (Peralta, 2007, p. 14) - pode contribuir para a sedimentação de valores mais ou menos democráticos.

Considerando isso, o que se observou a partir dos dados é que as iniciativas de justiça de transição indicam ser importantes não para uma construção de uma única narrativa sobre o período autoritário, visto que há uma disputa entre narrativas (Pollak, 1992), mas ao menos para a ideia de que se precisa conhecer o passado autoritário e suas consequências, a fim de não negá-lo e, mais importante, rechaçá-lo frente à democracia.

Entretanto, mais do que a adoção de uma ou outra medida de justiça de transição, parece que o momento de sua adoção tem peso maior nesse processo. Percebe-se que a contribuição positiva foi mais frutífera nos países que adotaram, desde o início da transição, iniciativas e mecanismos que abordam o tema do autoritarismo e seus legados de uma perspectiva coletiva, contribuindo para o aprendizado das novas gerações. 
Isso significa dizer que a justiça de transição é uma variável interveniente, cujas práticas e iniciativas voltadas à criação de uma memória coletiva em torno do autoritarismo e seus legados podem ser considerados condição necessária, mas não suficiente, para a construção de uma cultura política que valorize a democracia.

Sobre a memória enquanto elemento que tem implicações para a construção de uma cultura política mais ou menos democrática em um país, é preciso destacar, ainda, que a memória social é algo dinâmico, e os significados atribuídos ao passado não são imutáveis. A depender das guerras de memória (Mazzucchi, 2011; Ricoeur, 2007) e quem está vencendo a disputa para a construção de uma narrativa mais difundida sobre determinados eventos, há possibilidade de alteração na leitura desse passado, o que pode contribuir, no longo prazo, para a sedimentação de valores mais ou menos democráticos no futuro.

Ressalta-se, ainda, que não há processo transicional perfeito. Há o que é possível ser feito dentro das condições políticas e disputas no país. Portanto, o processo não é linear, com avanços e recuos mesmo nos casos considerados de maior sucesso em termos de iniciativas adotadas, a exemplo da Argentina.

Ademais, o fato de ainda existirem debates sobre o tema até o presente momento, como tem ocorrido no Brasil, Chile e Uruguai, significa que o assunto nunca será uma ferida completamente cicatrizada. Neste sentido, não é possível determinar um momento único em que a transição tenha terminado e os legados autoritários superados. Como demonstra a emergência de um revisionismo histórico que tenta negar a própria natureza política do fascismo, a narrativa da história e a construção das bases da democracia são uma disputa constante, como a pedra de Sísifo.

\section{Referências}

ABRÃO, Paulo; GENRO, Tarso. Justiça de Transição. In: AVRITZER, Leonardo et al. Dimensões políticas da justiça. Rio de Janeiro: Civilização Brasileira, 2013.

ABRÃO, Paulo; TORELLY, Marcelo D. Mutações do conceito de anistia na justiça de transição brasileira: a terceira fase da luta pela anistia. In: FICO, Carlos et al. Violência na História: Memória, trauma e reparação. Rio de Janeiro: Ponteio, 2012.

. As dimensões da Justiça de Transição no Brasil, a eficácia da Lei de Anistia e as alternativas para a verdade e justiça. In: A Anistia na era da responsabilização: o Brasil em perspectiva internacional e comparada. Brasília/Oxford: Ministério da Justiça, Comissão de Anistia/Oxford University, Latin America Centre, 2011.

ACUÑA, Carlos et al. Militares en la transición argentina: del gobierno a la subordinación constitucional. In: ACUÑA, Carlos (Org.). Juicio, castigo y memorias: Derechos humanos y justicia en la política argentina. Buenos Aires: Ediciones Nueva Visión, 1995.

AGUILA, Gabriela. La dictadura militar argentina: interpretaciones, problemas, debates. Páginas - Revista Digital de la Escuela de Historia - UNR, año 1, n. 1, p. 9-27, 2008.

AGUILAR, Paloma; BALCELLS, Laia; CEBOLLA, Héctor. Las actitudes de los españoles ante las medidas de justicia transicional relativas a la Guerra civil y al franquismo. Revista Internacional de Sociología, v. 69, n. 1, p. 59-90, 2011. 
ARAUJO, Maria Paula. Comissões de Verdade: um debate ético-político na contemporaneidade. In: FICO, Carlos et al. Violência na História: Memória, trauma e reparação. Rio de Janeiro: Ponteio, 2012.

BAQUERO, Marcello. Memória política e constituição da cultura brasileira. Ciências Sociais Unisinos, v. 48, n. 2, p. 84-92, 2012.

A Cultura Política na agenda da Democratização na América Latina. In:

(Org.). Cultura(s) Política(s) e democracia no século XXI na América Latina. Porto Alegre: Editora da UFRGS, 2011a.

Padrões de constituição da Cultura Política na América Latina no século XXI. In: Cultura(s) Politica(s) e democracia no século XXI na América Latina. Porto Alegre: Editora da UFRGS, $2011 \mathrm{~b}$.

BAQUERO, Marcello; GONZÁLEZ, Rodrigo S. Eleições, estabilidade democrática e socialização política no Brasil: análise longitudinal da persistência de valores nas eleições presidenciais de 2002 a 2010. Opinião Pública, v. 17, n. 2, p. 369-399, 2011.

BARAHONA, Alexandra. Justiça transicional e a política da memória: uma visão global. Revista Anistia Política e Justiça de Transição, n. 1, p. 56-83, 2009.

BARAHONA, Alexandra; SZNAJDER, Mario. The Politics of the past: The Southern Cone and the Southern Europe in comparative perspective. South European Society Politics, v. 15, n. 3, p. 487-505, 2010.

BARBOSA, Ana Carolina C. P. P.; CARVALHO, Claudia Paiva; FREITAS, Hellen C. R. Chile - Panorama da Justiça de Transição em 2015. In: CARVALHO, Claudia Paiva; GUIMARÃES, José Otávio Nogueira; GERRA, Maria Pia (Orgs.). Justiça de transição na América Latina: panorama 2015. Brasília: Ministério da Justiça, Comissão de Anistia, Rede Latino-Americana de Justiça de Transição (RLAJT), 2016.

BRASIL. Decreto $n^{\circ} 7.037$, de 21 de dezembro de 2009. Programa Nacional de Direitos Humanos (PNDH - 3).

CALDEIRA, Teresa Pires do Rio. Direitos humanos ou "privilégios de bandidos". Novos Estudos Cebrap, v. 30, n. 1991, p. 162-74, 1991.

CAMACHO, Fernando. Memorias enfrentadas: las reacciones a los informes Nunca Más de Argentina y Chile. Persona y Sociedad, v. 22, n. 2, p.67-99, 2008.

CARVALHO, Claudia Paiva. Brasil - Panorama da Justiça de Transição em 2015. In:

CARVALHO, Claudia Paiva; GUIMARÃES, José Otávio Nogueira; GERRA, Maria Pia (Orgs.). Justiça de transição na América Latina: panorama 2015. Brasília: Ministério da Justiça, Comissão de Anistia, Rede Latino-Americana de Justiça de Transição (RLAJT), 2016.

CERVEIRA, Neusah. Rumo à Operação Condor - Ditadura, tortura e outros crimes. Projeto História, n. 38, p. 97-118, 2009.

CORBO, Daniel. La transición de la dictadura a la democracia en el Uruguay. Perspectiva comparada sobre los modelos de salida política en el Cono Sur de América Latina.

Humanidadaes: revista de la Universidad de Montevideo, año 7, p. 23-47, 2007.

COSTA, Maíra Pereira. Justiça de Transição e Cultura Política no Cone Sul: Quando o passado encontra o presente. Dissertação de Mestrado. Universidade Federal do Rio Grande do Sul, 2018.

DAHÁS, Nashla. A Transição democrática e a construção da memória do pré-golpe no 
Chile. In: XVIII Encontro Regional, ANPUH. Mariana, 2012.

DALBORA, José Luiz Guzmán. Chile. In.: AMBOS, Kai; MALARINO, Ezequiel; ELSNER, Gisela (Orgs.). Justicia de Transición: com informes de América Latina, Alemania, Italia e España. Montevideo: Fundación Konrad-Adenauer, 2009.

DEL RÍO, Andrés. Justiça Transicional no Uruguai: os labirintos da dimensão da justiça (1985-2016). Revista Política Hoje, v. 25, n. 2, p. 21-54, 2015.

DE SOUZA, Fabiano Farias. Operação Condor: Terrorismo de Estado no Cone Sul das Américas. AEDOS, v. 3, n. 8, p. 159-176, 2011.

DOUGLAS, Mary. Pureza e Perigo. São Paulo: Perspectiva, 1976.

DUQUE, Ana Paula Del Vieira; CARVALHO, Claudia Paiva. Argentina - Panorama da Justiça de Transição em 2015. In: CARVALHO, Claudia Paiva; GUIMARÃES, José Otávio Nogueira; GERRA, Maria Pia (Orgs.). Justiça de transição na América Latina: panorama 2015. Brasília: Ministério da Justiça, Comissão de Anistia, Rede Latino-Americana de Justiça de Transição (RLAJT), 2016.

ELSTER, Jon. Closing the books: Transitional justice in historical perspective. Cambridge: Cambridge University Press, 2004.

GALAIN PALERMO, Pablo. El proceso de Justicia Transicional em Uruguay. Verba Iuris, v. 32, p. 33-44, 2014.

La Justicia de Transición en Uruguay: Un conflicto sin resolución. Revista de Derecho, n. 6, p. 109-153, 2011.

Uruguai. In.: AMBOS, Kai; MALARINO, Ezequiel; ELSNER, Gisela (Orgs.). Justicia de Transición: com informes de América Latina, Alemania, Italia e España. Montevideo: Fundación Konrad-Adenauer, 2009.

GALLO, Carlos Artur. A história no banco dos réus: leis de impunidade, memória da repressão política e as decisões da Suprema Corte na Argentina e no Brasil. Tese de Doutorado. Universidade Federal do Rio Grande do Sul, 2016.

GEORGE, Alexander L.; ALEXANDER, A. Case studies and theory development in the social sciences. Cambridge: MIT Press, 2005.

GONÇALVES, Danyelle Nilin. Os sentidos e as disputas em torno da Anistia e da Reparação de perseguidos políticos no Brasil. In: GALLO, Carlos Artur; RUBERT, Silvania (Orgs.). Entre a memória e o esquecimento - estudos sobre os 50 anos do Golpe Civil-Militar no Brasil. Porto Alegre: Editora Deriva, 2014.

GONZÁLEZ, Rodrigo S. A política de promoção aos direitos humanos no Governo Lula. Revista Debates, v. 4, n. 2, p. 107-135, 2010.

Direitos Humanos e a democracia na transição brasileira: OAB, CNBB e Anistia Internacional. Dissertação de Mestrado. Universidade Federal do Rio Grande do Sul, 1994.

GREIFF, Pablo de. Theorizing transitional justice. Nomos, v. 51, p. 31-77, 2012.

GUEMBE, María José. Reabertura dos processos pelos crimes da ditadura militar Argentina. SUR. Revista internacional de direitos humanos, v. 2, n. 3, p. 120-137, 2005.

GUNTHER, Richard; MONTERO, José Ramón. Legitimidade política em novas democracias. Opinião pública, v. 9, n.1, p. 1-43, 2003.

HELD, David. Modelos de Democracia. Belo Horizonte: Ed. Paidéia, 1987. 
HITE, Katherine; MORLINO, Leonardo. Problematizing the links between authoritarian legacies and "good" democracy. In: HITE, Katherine; CESARINI, Paola (Eds.). Authoritarian Legacies and Democracy in Latin America and Southern Europe. Notre Dame: University of Notre Dame Press, 2004.

HUNTINGTON, Samuel P. A Terceira Onda: democratização no final do século XX. São Paulo: Ática, 1994.

LAFER, Celso. Justiça, História, Memória: reflexões sobre a Comissão da Verdade. In: FICO, Carlos et al. Violência na História: Memória, trauma e reparação. Rio de Janeiro: Ponteio, 2012.

LAVILLE, Christian; DIONNE, Jean. A construção do saber: manual de metodologia de pesquisa em ciências humanas. Porto Alegre/Belo Horizonte: Artmed/Editora UFMG, 1999.

LENTZ, Rodrigo. A Justiça de Transição do Jeitinho Brasileiro: panorama após 50 anos do Golpe Civil-Militar de 1964. In: GALLO, Carlos Artur; RUBERT, Silvania (Orgs.). Entre a memória e o esquecimento - estudos sobre os 50 anos do Golpe Civil-Militar no Brasil. Porto Alegre: Editora Deriva, 2014.

LINZ, Juan J. Del Autoritarismo a la Democracia. Estudios Públicos, n. 23, p. 5-58, 1986.

MACHADO, Patrícia da Costa. Justiça de Transição no Brasil: a atuação do Supremo Tribunal Federal e a reinterpretação da Lei da Anistia na ADPF nº153. In: GALLO, Carlos Artur; RUBERT, Silvania (Orgs.). Entre a memória e o esquecimento - estudos sobre os 50 anos do Golpe Civil-Militar no Brasil. Porto Alegre: Editora Deriva, 2014.

MAZZUCCHI, Maria Leticia. Políticas da memória e políticas do esquecimento. Aurora Revista de Arte, Mídia e Política, n. 10, p. 102-118, 2011.

MENDES, Ricardo Antonio. Ditaduras civil-militares no Cone Sul e a Doutrina de Segurança Nacional - algumas considerações sobre a Historiografia. Revista Tempo e Argumento, v. 5, n. 10, p. 06-38, 2013.

MEZAROBBA, Glenda. De que se fala, quando se diz "Justiça de Transição"?. BIB, n. 67, p. 111-122, 2009.

MOISÉS, José Álvaro. Cultura Política, Instituições e Democracia: Lições da experiência brasileira. $R B C S$, v. 23, n. 66, p. 11-43, 2008.

Os Brasileiros e a Democracia. São Paulo: Ática, 1995.

MORLINO, Leonardo. Authoritarian Legacies, Politics of the Past and the Quality of Democracy in Southern Europe: open conclusions. South European Society and Politics, v. 15, n. 3, p. 507-529, 2010.

NAPOLITANO, Marcos. 1964: História do Regime Militar brasileiro. São Paulo: Contexto, 2014.

NOGUEIRA, Amanda Raquel Alves; CARVALHO, Claudia Paiva. Uruguai - Panorama da Justiça de Transição em 2015. In: CARVALHO, Claudia Paiva; GUIMARÃES, José Otávio Nogueira; GERRA, Maria Pia (Orgs.). Justiça de transição na América Latina: panorama 2015. Brasília: Ministério da Justiça, Comissão de Anistia, Rede Latino-Americana de Justiça de Transição (RLAJT), 2016.

NOVARO, Marcos; PALERMO, Vicente. A ditadura militar argentina 1976-1983: do golpe de Estado à restauração democrática. São Paulo: EdUSP, 2007.

O'DONNELL, Guillermo, SCHIMITTER, Philippe C., WHITEHEAD, Laurence (Eds). 
Transições do regime autoritário - Sul da Europa. São Paulo: Vértice, 1988.

(Eds). Transições do regime autoritário - América Latina. São Paulo: Vértice, 1987.

OLSEN, Tricia; PAYNE, Leigh A.; REITER, Andrew G. The Justice Balance: When Transitional Justice Improves Human Rights and Democracy. Human Rights Quartely, v. 32, n. 4, p. 980-1007, 2010.

ONU. Security Council. The rule of law and transitional justice in conflict and post-conflict societies. Report of the Secretary-General. S/2004/616. New York: ONU, 2004.

PADRÓS, Enrique Serra. Terrorismo de Estado: reflexões a partir das experiências das Ditaduras de Segurança Nacional. In: GALLO, Carlos Artur; RUBERT, Silvania (Orgs.). Entre a memória e o esquecimento - estudos sobre os 50 anos do Golpe Civil-Militar no Brasil. Porto Alegre: Editora Deriva, 2014.

Repressão e violência: Segurança Nacional e terror de Estado nas ditaduras latinoamericanas. In: FICO, Carlos et al. Ditadura e Democracia na América Latina: balanço histórico e perspectivas. Rio de Janeiro: Editora FGV, 2008.

PAIVA, Denise; SOUZA, Marta Rovery; LOPES, Gustavo de Faria. As percepções sobre Cidadania, Democracia e Direitos. Opinião Pública, v. X, n. 2, p. 368-376, 2004.

PAIXÃO et al (Orgs.). Relatório 2014. Brasília: Ministério da Justiça, Comissão de Anistia, Rede Latino-Americana de Justiça de Transição (RLAJT), 2015.

PARENTI, Pablo, F.; PELLEGRINI, Lisandro. Argentina. In: AMBOS, Kai; MALARINO, Ezequiel; ELSNER, Gisela (Orgs.). Justicia de Transición: com informes de Amérca Latina, Alemania, Italia y España. Montevideo: Fundación Konrad-Adenauer, 2009.

PERALTA, Elsa. Abordagens teóricas ao estudo da memória social: uma resenha crítica. Arquivos da Memória, n. 2, p. 4-23, 2007.

PINTO, António Costa; MARTINHO, Francisco Carlos Palomanes. O passado que não passa: a sombra das ditaduras na Europa do Sul e na América Latina. Rio de Janeiro: Civilização Brasileira, 2014.

PINTO, Céli Regina Jardim. Teorias da democracia: diferenças e identidades na contemporaneidade. Porto Alegre: EDIPUCRS, 2004.

Democracia como significante vazio: a propósito das teses de Ernesto Laclau e Chantal Mouffe. Sociologias,v. 1, n. 2, p. 68-99, 1999.

POLLAK, Michael. Memória e Identidade Social. Revista Estudos Históricos, v. 5, n. 10, p. 200-215, 1992.

RICOEUR, Paul. A memória, a história, o esquecimento. Campinas: Ed. Unicamp, 2007.

ROJAS, Claudio Nash. La transición chilena y justicia transicional: Análisis crítico. Derecho \& Sociedad, n. 47, p. 129-144, 2016.

RUBERT, Silvania. "Para reconciliar, é preciso esquecer?": reflexões sobre as possibilidades de resgate da memória da repressão política no Brasil. In: GALLO, Carlos Artur; RUBERT, Silvania (Orgs.). Entre a memória e o esquecimento - estudos sobre os 50 anos do Golpe Civil-Militar no Brasil. Porto Alegre: Editora Deriva, 2014.

SANTOS, Everton; BAQUERO, Marcello. Democracia e Capital Social na América Latina: Uma análise comparativa. Revista de Sociologia e Política, n. 28, p. 221-243, 2007.

SCHUMPETER, Joseph A. Capitalismo, Socialismo e Democracia. Rio de Janeiro: Zahar, 
1984.

SOSA, Ana María; MAZZUCCHI, Maria Leticia. Derecho de memoria y búsqueda de la verdade: un estúdio comparativo entre Brasil y Uruguay. Revista Diálogos, v. 16, n. 3, p. 873896, 2012.

SOUZA, Bruno Mello; GALLO, Carlos Artur. Legados Culturais do Autoritarismo no Cone Sul. Revista Sul-Americana de Ciência Política, v. 2, n. 2, p. 75-89, 2015.

TEITEL, Ruti. Transitional Justice Genealogy. Harvard Human Rights Journal, v. 16, p. 6994, 2003.

THE WORLD VALUES SURVEY ASSOCIATION. World Values Survey [Online]. 2019. Disponível em: http://www.worldvaluessurvey.org/wvs.jsp. Acesso em: 15 jan. 2019.

ZYL, Paul Van. Promovendo a justiça transicional em sociedades pós-conflito. Revista Anistia Política e Justiça de Transição, n. 1, p. 32-55, 2009.

\author{
Artigo submetido em: Abril/2019 \\ Artigo aceito em: Julho/2019
}

\begin{abstract}
Maíra Pereira da Costa (mairapcostaa@gmail.com) é Doutoranda e Mestre em Ciência Política pela Universidade Federal do Rio Grande do Sul (UFRGS).
\end{abstract}

Rodrigo Stumpf González (rodrigo.stumpf@ufrgs.br) é professor no Programa de PósGraduação em Ciência Política da Universidade Federal do Rio Grande do Sul (UFRGS). Doutor em Ciência Politica pela mesma instituição.

\title{
Justiça de Transição, Cultura Política e Legado Autoritário no Cone Sul
}

Resumo. Com o fim de regimes autoritários e emergência de democracias, a partir de meados da década de 1970, surgiram estudos sobre as transições para o regime democrático, voltados tanto ao processo de (re)criação de instituições democráticas quanto à consolidação da democracia. Surgiram também estudos sobre Justiça de Transição, compreendendo iniciativas adotadas frente ao passado autoritário. O objetivo do presente artigo é discutir a relação entre Justiça de Transição e cultura política, a partir da utilização de instrumentos como forma de incidir sobre os legados autoritários e transformá-los com vistas à construção de uma cultura política que favoreça a democracia. Analisou-se comparativamente as iniciativas de justiça de transição adotadas por Argentina, Brasil, Chile e Uruguai e sua relação com a cultura política, utilizando dados do World Values Survey e a cobertura feita pelos principais jornais destes países. Discutiu-se, portanto, a relação entre as distintas formas como cada país lidou com o passado autoritário e as características de sua cultura política, apontando indícios que permitem apontar o uso da justiça de transição como elemento de socialização política favorável à democracia.

Palavras chave: Democracia; Justiça de Transição; Legado Autoritário; Memória. 


\title{
Transitional Justice, Political Culture and Authoritative Legacy in the Southern Cone
}

\begin{abstract}
With the end of authoritarian regimes and the rise of democracies since the mid1970s, studies on transitions to the democratic regime have emerged, focusing both on the creation of democratic institutions and on the consolidation of democracy. There were also studies on Transitional Justice, including initiatives taken against the authoritarian past. The aim of this article is to discuss the relationship between Transitional Justice and political culture, using instruments as a way to focus on authoritarian legacies and transform them into building a political culture that favors democracy. There were made comparative analysis of the transitional justice initiatives adopted by Argentina, Brazil, Chile and Uruguay, and their relationship with the political culture, using data from the World Values Survey and the coverage by the main newspapers of these countries. Therefore, the relationship between the different ways in which each country dealt with the authoritarian past and the characteristics of its political culture was pointed out, that indicate the use of transitional justice as an element of political socialization favorable to democracy.
\end{abstract}

Keywords: Democracy; Transitional Justice; Authoritarian Legacy; Memory. 